\title{
Intelligent transportation-deployment and development process in Korea
}

\author{
A. A. Shah ${ }^{1}$, N. P. Mahalik ${ }^{2}$, J. Namkoong ${ }^{3} \&$ J. D. Lee ${ }^{1}$ \\ ${ }^{1}$ School of Civil, Urban and Environmental Engineering, \\ Yeungnam University, Republic of Korea \\ ${ }^{2}$ Department of Mechatronics, \\ Gwangju Institute of Science and Technology, Republic of Korea \\ ${ }^{3}$ Korea Highway Corporation, Republic of Korea
}

\begin{abstract}
Intelligent Transport Systems (ITS) are intended to help solve various road transportation problems, by linking the road and vehicles through advanced communications and information technologies so as to achieve safer, more efficient transportation. ITS infrastructure deployment in Korea was initiated in the early 1990s and Korea proposed her first National ITS Master Plan in 1997 with a revised version in the year 2000 for a period of 20 years. The prime goal is to enhance safety, increase transportation efficiency, improve driving comfort and reduce environmental pollution. This paper reviews different stages of ITS development in Korea and checks the performance of the tools in improving the overall traffic functioning. The intended audiences are the policy makers, practioners and all those who want to see the applicability of this IT based sustainable solution to mitigate traffic problem intelligently.

Keywords: intelligent transport system, Republic of Korea, planning.
\end{abstract}

\section{Introduction}

The Republic of Korea is a densely populated country of about 48 million inhabitants located in East Asia. The process of rapid industrialisation over the last few decades transformed Korea into an economic hub of Asia. In the area of information technology she has demonstrated particular strength that has trickled down into every major arena with transportation as no exception. Korean domestic research on Intelligent Transport Systems (ITS) was initiated in early 
1990s with the installation and operation of freeway traffic management system at Gyongbu expressway (from Seoul to Daejeon) as the first major project. Since then, ITS development has been careful and systematic based on ensuring efficiency, connectivity and compatibility.

Intelligent Transportation intellectualizes existing transportation infrastructure thus enhancing its capacity and offsetting the additional traffic by better management to ensure sustainable use of the resources. ITS integrate all individual entities that are related with the mobility such as physical infrastructure, vehicles and controlling agencies employing information technology to perform as a comprehensive system. It is a multidisciplinary approach that extends through the knowledge basis in many conventional areas like civil engineering, physical planning and development, communication, information technology and management, satellite technology, finance and public sector policy development.

Korea started ITS from the acquired foreign technology but focused on development of an indigenous technology compatible with the local needs. This paper reviews the backdrop in which ITS was explored as a supplementary option to tackle mobility problem in Korea resulting from her spectacular economic growth instigating subsequent vehicular increase in early 1990s. In later sections a glimpse of ITS plan and its impacts shall be provided.

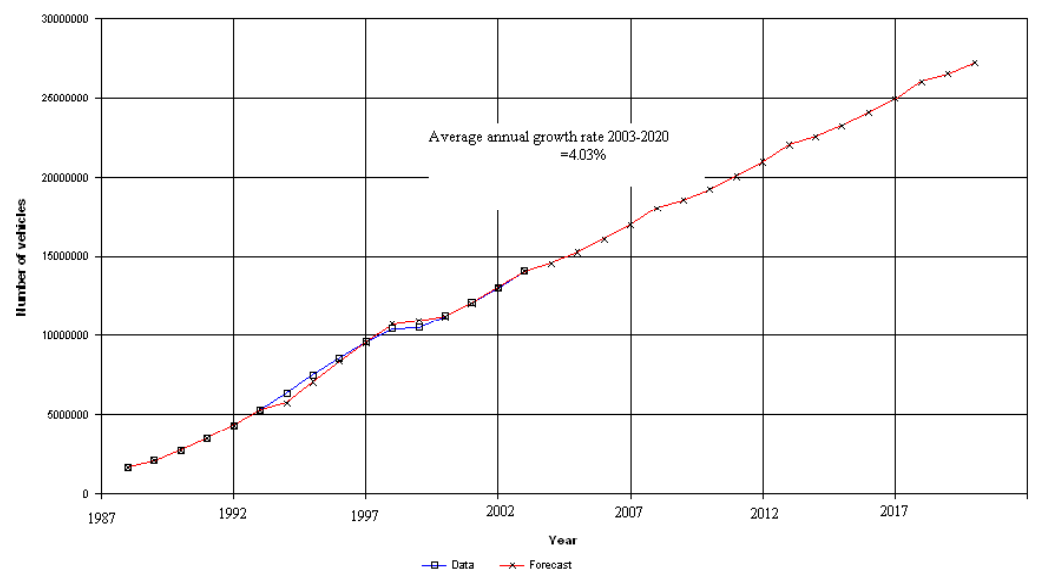

Figure 1: $\quad$ Traffic growth in Korea.

\section{Traffic growth in Korea}

In Korea, motorization has been growing between 1988 and 2003 at an average annual rate of $14.36 \%$ (Figure 1). During last few years, the growth rate has declined to almost 7.5\% and employing Winter's Additive Season algorithm that 
best fit the curve of the historical data, it can be anticipated to further decrease to $4.03 \%$ by the year 2020; still leading to volume as high as 28 million vehicles, which is almost double of its present size.

This enormous volumetric increase coupled with the estimated increase in domestic traffic loads by 3 times, 2.2 times in domestic passenger and 3.8 times in freight from 1997 to 2011 [1] employs that both inter-city and intra-city mobility problem along with environmental degradation are bound to amplify in years to come.

\section{Mobility problems}

Congestion, accidents and environment degradation are reckoned as major mobility problems in Korea that are associated with enormous increase of traffic in the past two decades. These problems are discussed in greater depth below.

\subsection{Congestion}

The road traffic scenario has been viewed as a major drag on the competitiveness of the country's economy. The enhanced freight traffic because of rapid economic growth and expanding international trade is not appropriately regulated and balanced with ample supply of infrastructure. Logistics cost are a major burden which is estimated as 12.8 percent, comparing with 9.6 percent in Japan and 10.1 percent in the United States and it is speculated to rise twice as much as those of advanced countries [2].

The cost of congestion is about 4.4 percent of GDP that amounts to US\$ 41 billion considering the latest available statistics for the year $2003 \mathrm{~km}$, 4] It implies that for a population of 48 million and about 14 million registered vehicles the imposed yearly congestion cost on every individual is about US $\$ 850$ and on every vehicle is about US\$2900. This cost is significantly higher as was estimated elsewhere [1] based on 1994 estimates.

\subsection{Accidents}

Road traffic accidents have posed a major threat to the well being of Korean society. In 2000 road traffic injuries was the fourth leading cause of death after cancer, stroke and heart disease [5]. As per 2002 OECD available statistics [6], Korea had the highest fatalities and injuries rate of all 30 OECD member countries when compared against the total number of vehicles (Table 1). The fatality rate varies from 1.6 times (in case of USA) to 13 times (in case of Japan). Similarly injuries levels are also reported alarmingly higher especially when comparison involves other parameters like population and length of the network. 
Table 1: $\quad$ Accident data of selected OECD countries.

\begin{tabular}{|c|c|c|c|c|c|c|c|}
\hline \multirow[t]{2}{*}{ Country } & \multirow{2}{*}{$\begin{array}{l}\text { Population } \\
\text { (Millions) }\end{array}$} & \multirow{2}{*}{\begin{tabular}{|l|} 
Length \\
of \\
Expres \\
sway \\
$(\mathrm{kms})$ \\
\end{tabular}} & \multirow{2}{*}{$\begin{array}{l}\text { Number } \\
\text { of motor } \\
\text { vehicles } \\
(1000)\end{array}$} & \multicolumn{2}{|c|}{ Injuries } & \multicolumn{2}{|c|}{ Killed } \\
\hline & & & & Number & $\begin{array}{l}/ 100000 \\
\text { Vehicles }\end{array}$ & Number & $\begin{array}{l}/ 100000 \\
\text { Vehicles }\end{array}$ \\
\hline $\begin{array}{l}\text { Republic of } \\
\text { Korea }\end{array}$ & 47.6 & 3060 & 14614 & 7740 & 53.0 & 583 & 4.0 \\
\hline USA & 288.4 & 74807 & 225685 & 134000 & 59.4 & 5749 & 2.5 \\
\hline Canada & 31.4 & 16900 & 18617 & 12670 & 68.1 & 445 & 2.4 \\
\hline Italy & 57.8 & 6478 & 42107 & 14761 & 35.1 & 758 & 1.8 \\
\hline France & 59.3 & 10068 & 35396 & 7596 & 21.5 & 579 & 1.6 \\
\hline $\begin{array}{l}\text { New } \\
\text { Zealand }\end{array}$ & 3.9 & 169 & 2710 & 398 & 14.7 & 11 & 0.4 \\
\hline Japan & 127.4 & 6915 & 80364 & 7480 & 9.3 & 270 & 0.3 \\
\hline
\end{tabular}

\subsection{Environment degradation}

Transportation also has adverse impacts on environment and is a major contributing factor in deteriorating its quality. Carbon dioxide emissions by the domestic freight only, injected 6612 thousand tons of carbon in the year 2000 and are projected twice in the next 20 years if not intervened. [7]. Table 2, below portrays road traffic induced greenhouse gases for 20 years starting from year 2000.

Table 2: $\quad$ Greenhouse gases emissions, 2000-2020 (thousand of tons).

\begin{tabular}{|l|l|l|l|l|l|l|l|}
\hline & Year & $\mathrm{NO}_{\mathrm{x}}$ & $\mathrm{CH}_{4}$ & NMVOC & $\mathrm{CO}$ & $\mathrm{N}_{2} \mathrm{O}$ & $\mathrm{CO}_{2}$ \\
\hline \multirow{2}{*}{$\begin{array}{l}\text { Car, bus } \\
\text { and } \\
\text { truck } \\
\text { emission }\end{array}$} & 2000 & 345.1 & 7.7 & 155.7 & 786.6 & 7.9 & 64,599 \\
\cline { 2 - 8 } & 2005 & 389.0 & 9.0 & 187.0 & 956.8 & 10.2 & 76,401 \\
\cline { 2 - 8 } & 2010 & 445.8 & 10.6 & 222.9 & $1,152.3$ & 13.0 & 91,276 \\
\cline { 2 - 8 } & 2015 & 516.5 & 12.3 & 259.2 & $1,340.5$ & 15.1 & 105,932 \\
\cline { 2 - 8 } & 2020 & 571.0 & 13.6 & 288.1 & $1,490.6$ & 16.8 & 117,379 \\
\hline
\end{tabular}

Source: Extracted from [7].

$\left(\mathrm{CH}_{4}\right.$ : methane; $\mathrm{CO}$ : carbon monoxide; $\mathrm{CO}_{2}$ : carbon dioxide; $\mathrm{N}_{2} \mathrm{O}$ : nitrous oxide; NMVOCs: non-methane volatile organic compounds; $\mathrm{NO}_{\mathrm{x}}$ : oxides of nitrogen.) 


\section{Solution}

\subsection{Physical infrastructure extension}

The conventional approach to tackle this alarming traffic growth and the subsequent mobility problems has been the provision and extension of the physical infrastructural network. As per [8], in 1981 the total length of the roads was about $50336 \mathrm{~km}$ that has increased to $97252 \mathrm{~km}$ by 2003 at an average annual rate $3.04 \%$, thereby yielding a net density as $0.98 \mathrm{~km}$ per square kilometres. During the last couple of years, Korean government has taken an ambitious plan to make world's first class transport network that will not only ensure safety and convenience but also balanced regional development and sustainable land use [9]. The tangible impacts of this policy effectuation include doubling of current approximately $3000 \mathrm{~km}$ expressway network by 2020 , expansion of the national highway and special greater city roads, provincial roads and city-county roads network to ensure the major corridor accessibility within 30 minutes from anywhere in the country.

\subsection{ITS development Strategy}

Korean government has patronized Intelligent Transport System throughout the country and in particularly at all major road networks. Korea prepared a comprehensive promotion plan in mid 1990s focusing spatiotemporal phased development approach of ITS services in three distinct stages from 1996 to 2010. The stages are: basic construction stage (1996 2000), growth and enhancement stage (2001 2005) and upgrade and maturation phase (2006 2010) [10]. National ITS master plan was prepared in September 1997 encapsulating all three stages of the promotion plan and the strategic guidelines for the ITS architecture in the country identifying the key stakeholders with their liabilities. The landmark achievements of ITS progression are outlined below:

- Statutory umbrella with the Transport System Efficiency Act, 1999.

- Establishment of ITS Korea in April 1999 to beef up a mutual cooperation between public and private sectors for an efficient and sustainable development of ITS.

- National ITS Master Plan for the $21^{\text {st }}$ century in December 2000.

The National ITS Master Plan is a revised version of the 1997's Master Plan that extends up to 2020 and its salient features are discussed implicitly here.

\section{National ITS Master Plan for the $21^{\text {st }}$ century}

A National ITS Master Plan for the $21^{\text {st }}$ century has been formulated in December 2000 as a blueprint for ITS development in the country. The scope of the plan ranges from local to national level to mitigate both immediate traffic problems as well as projected future mobility threats from the long-term perspective. The plan aims to provide a strategic guideline for the development of ITS areas, time schedule and budgets. 


\subsection{Service areas}

It singles out 7 potential areas for the deployment and development of ITS with 18 services that further yields to 62 sub-services. The core areas and services are shown in Figure 2.

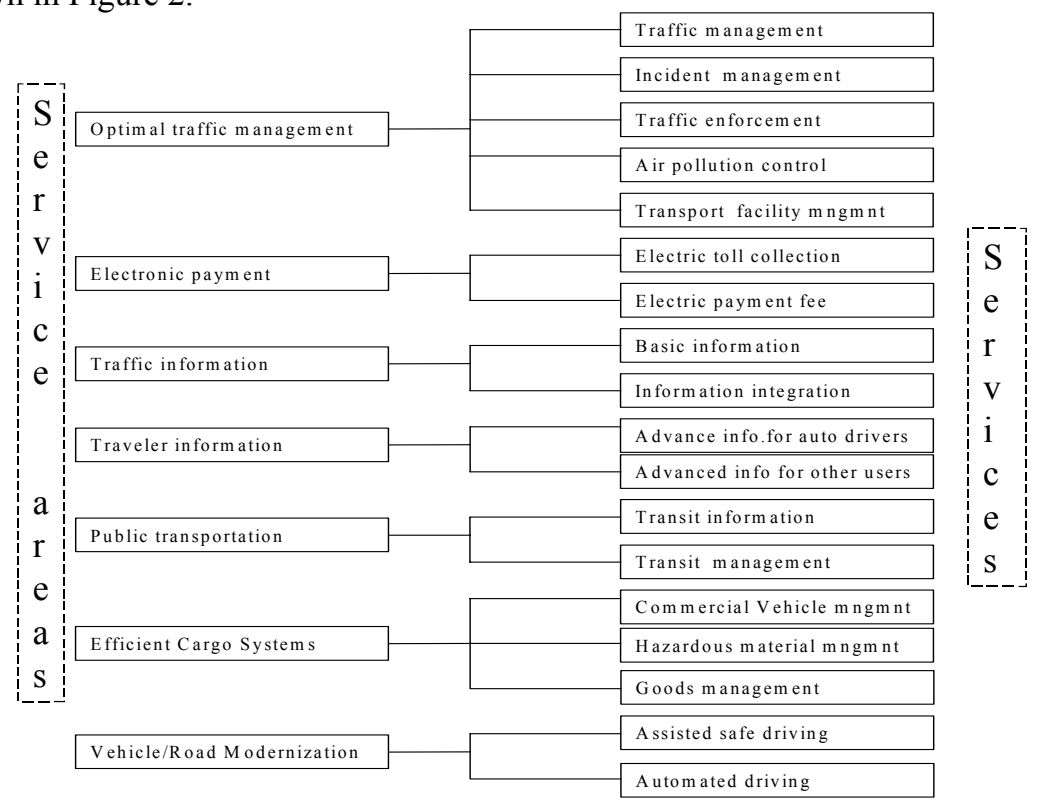

Figure 2: $\quad$ Service areas and services of the plan.

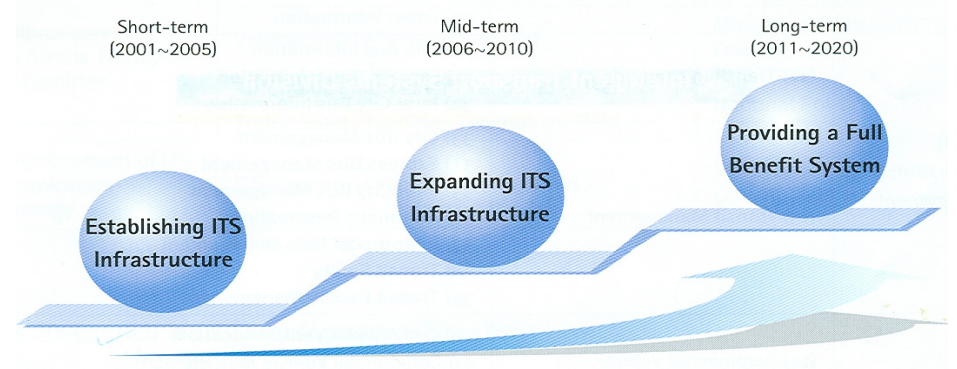

Figure 3: $\quad$ Scheduling of ITS in Korea.

\subsection{Time scheduling}

The time horizon for the National ITS Master Plan for the $21^{\text {st }}$ century is selected as 20 years starting from the year 2001 (Figure 3, taken from [10]). It is divided 
into short (2001 2005) that corresponds to Phase 1, Mid-term (2006-2010) corresponding to Phase 2 and long-term (2011-2020) as Phase 3. Like the first national plan of 1997, each of these phases is aimed towards achieving specific goals. The plan Phase 1, suggests developments on various fundamental infrastructural. Phase 2 will lead to the expansion of the various applications of ITS while Phase 3 carries the expansion into a full-scale maturity of the system with enhanced stability and delivery of the envisaged level of service to the user.

\subsection{Budgets}

The estimated cost for the entire plan up until the year 2020 is 8.34 trillion Korean won. (US\$6.67 billion) (The plan was developed in 2000. Therefore, average exchange rate for that year with US\$1 equals to 1,250 Korean Won is applied for calculation.) The first phase of the plan earmarked 1.68 trillion Korean won with further more than 2 trillion Korean won in next 5 years and about 4.5 trillion Korean won by 2020 . The plan identifies investment guidelines in the aforesaid 7 key service areas as shown in the Table 3 with the significant contribution from all three major stakeholders, that is, central government, local government and private sector.

Table 3: $\quad$ Investment plan (Billion Korean won).

\begin{tabular}{|l|c|c|c|c|}
\hline Category/Year & $\begin{array}{c}\text { Phase 1 } \\
(2001-2005)\end{array}$ & $\begin{array}{c}\text { Phase 2 } \\
(2006-2010)\end{array}$ & $\begin{array}{c}\text { Phase 3 } \\
(2011-2020)\end{array}$ & Total \\
\hline Traffic Management & 1127.7 & 1527 & 3165.6 & 5820.3 \\
\hline Electronic Payment Systems & 98.6 & 225.1 & 388.5 & 712.2 \\
\hline Traffic Information & 110 & 60 & 60 & 230 \\
\hline Traveller Information & 100 & 100 & 336 & 536 \\
\hline Public Transportation & 78 & 96.5 & 224.7 & 3989.2 \\
\hline Efficient Cargo Systems & 55.4 & 52 & 0 & 107.4 \\
\hline Vehicle/Road Modernization & 111.3 & 113.3 & 311.8 & 536.4 \\
\hline Total & 1681 & 2173.9 & 4486.6 & 8341.5 \\
\hline
\end{tabular}

\section{Benefits of ITS}

\subsection{Improved Traffic functioning}

Three cities, Daejeon, Jeonju, and Jeju, were selected as models for the early deployment of ITS at an expense totalling 90.8 billion Korean won, with the central government supporting about $1 / 3$ of the costs, while local governments and private sector shared almost equally the remainder. Some of the impacts of ITS deployment are summarised in Table 4 below: 
Table 4: $\quad$ Effects of ITS.

\begin{tabular}{|l|l|l|l|}
\hline Impacts & Daejeon & Jeonju & Jeju \\
\hline Increase in travel speed & $19.3 \%$ & $35.6 \%$ & $6.1 \%$ \\
\hline Decrease in delays & $53 \%$ & $31.5 \%$ & $31.9 \%$ \\
\hline Increase in citizen's satisfaction & $27.3 \%$ & $22.9 \%$ & $22.3 \%$ \\
\hline
\end{tabular}

\subsection{Enhanced road safety}

There has been a significant improvement on the safety conditions on the road network in Korea since mid 1990s (Figure 4) that can be contributed to, inter alia, deployment of ITS applications. While no exact data is available that can attribute this relative increase level of safety to the deployment of the ITS, it is a $\mathrm{f}$ act that the improvement coincides with the implementation of ITS. It is reported [11] that in the wake of unmanned surveillance systems, death ratio of traffic accidents was reduced by $60 \%$ (107 persons $\rightarrow 43$ persons), accident reduced by $28 \%(801 \rightarrow 576)$

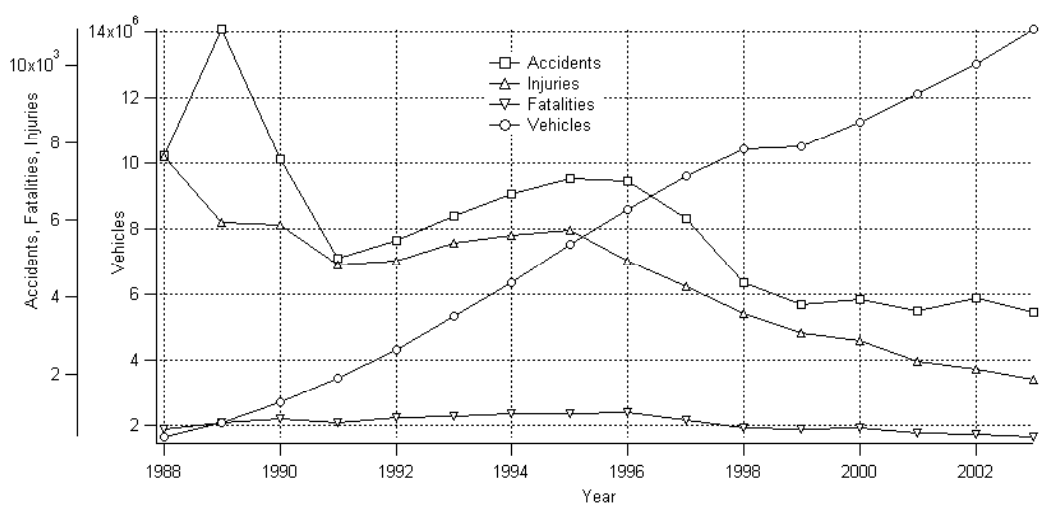

Figure 4: Enhanced safety on roads.

\section{Identification of the problem areas in the plan}

The ITS deployment in Korea has been exemplary that coincides with its booming information technology development era. This special status, even amongst the industrialised nations, has been duly acknowledged in literature [12]. However a recent review study [13] reports the following contentious issues:

- There has been an ambiguity over understanding of the potentials and limitations of ITS applications

- The plan does highlight certain service areas for investment in Phase 1, but such guideline is lacking in the subsequent phases of the plan. 
- There is also haziness upon the role of various stakeholders and their mutual coordination. This has been identified as one of the potential reason of the reduced investment as suggested in the plan. The plan anticipated an overall investment of about 1350 billion won in first four years but the received an actual investment of only 643 billion won that is $47 \%$ of the target investment (Figure 5).

- The response of general public toward adoption of the new technology was not as robust as it was anticipated in the plan. This clearly indicates a need of a more aggressive participation of the communities in order to effectuate the plan effectively.

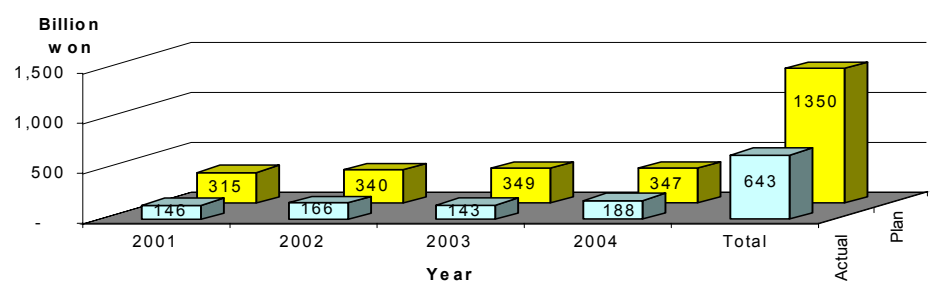

Figure 5: Comparison of actual and planed investment.

\section{Discussion and conclusions}

The pivotal role of mobility in inspiring the economic growth and development has been a key toward exploring the state-of-the art technologies that resulted in the emergence of intelligent transportation. Benefits of ITS have been realised in many industrialised countries that coped large volume of traffic flows efficiently and effectively reducing an overall cost of mobility, ensuring safety and preserving environment quality. At the moment, the sitting ITS technologies are limited to general applications like VDS, ETCS, and DRGS etc. The extension of these technologies and emergence of new avenues by connecting and integrating all individual system and technologies will reportedly generate US\$500 to US\$600 billion in economic benefits [14].

Considering the economic potentials of ITS and limited scope of the conventional approach from social, economical and environmental perspective, Korean government prepared the National ITS Master Plan for the $21^{\text {st }}$ century in the year 2000. The plan suggests a guideline for deploying basic infrastructure to yield a fully mature system in the country by the target year (2020). It identifies seven core service areas for the development and investment from national government, local governments and private sector. The experience of three model cities indicates a significant mitigation of the mobility problem. Nonetheless the plan has not still fully realised the envisaged benefits hitherto (Phase 1) mainly because of some ambiguity in the policy guidelines toward investment, institutional coordination and communities' participation and a closer study, to investigate these areas, is required. 


\section{References}

[1] Report: ATIP97.088, Korea Intelligent Transportation System (ITS) Plans Report published by Asian Technology Information Program, 1997

[2] NewsWorld, A Dream Transportation Comes True - KTX debut means Magic Bullet to transportation woes, January 2004, Online http://www.newsworld.co.kr/cont/0401/24.html,

[3] William D. Eggers, Peter Samuel, Rune Munk, "How Pricing Road Use Can Ease Congestion Combating Gridlock- Executive Summary” Deloitte Consulting. 2003, Online, http://www.dc.com/pdf/ Gridlock Exec Summary.pdf

[4] OECD statistics, "Gross Domestic Product, 2000”, Online, http://www1.oecd.org/publications/figures/2001/anglais/012 013 GDP.p $\underline{\mathrm{df}}$

[5] Yang Bong-Min, Kim Jinhyun, Road traffic accidents and Policy Interventions in Korea, Injury control and safety promotion, Vol 10 No. 12, pp89-94, 2003

[6] OECD - International Road Traffic and Accident Database, 2005 Brief Overview International Road Traffic and Accident Data, Online, http:/www.bast.de/htdocs/fachthemen/irtad/english/englisch.html

[7] Lee Sungwon, 2001 Improving Efficiency In The Logistics Sector For Sustainable Transport Development In The Republic Of Korea Transport and Communications Bulletin for Asia and the Pacific No.70

[8] http://moct.go.kr/EngHome/DataCenter/Statistic/Statistic01.htm

[9] MOCT Policies/policies2003, , Online, http://moct.go.kr/

[10] ITS Korea Intelligent Transport System In Korea -A Broachers Presented in 11 the World Congress on ITS Japan, 2004.

[11] ITS Korea Website http://www.itskorea.or.kr/eng/index.html

[12] Report, Inception report for revising Korean National ITS plan [translated name], Korea Research Institute for Human Settlements and other, 2005.

[13] Report: A comparison of Intelligent Transportation Systems Progress around the world, ITS America, 1997.

[14] Report: ATIP00.013, Intelligent Transportation Systems Applications, Report published by Asian Technology Information Program, 2000 